Leukemia (2018) 32:2058-2062

https://doi.org/10.1038/s41375-018-0191-0

Acute lymphoblastic leukemia

\title{
Whole-exome sequencing exploration of acquired uniparental disomies in B-cell precursor acute lymphoblastic leukemia
}

\author{
Kristina B. Lundin-Ström ${ }^{1} \cdot$ Andrea Biloglav $^{1} \cdot$ Henrik Lilljebjörn ${ }^{1}{ }^{1} \cdot$ Marianne Rissler $^{1} \cdot$ Thoas Fioretos $^{1,2}$. \\ Markus Hansson $\mathbb{D D}^{3} \cdot$ Mikael Behrendtz $^{4} \cdot$ Anders Castor $^{5} \cdot$ Linda Olsson $^{2} \cdot$ Bertil Johansson $^{1,2}$
}

Received: 12 April 2018 / Revised: 7 May 2018 / Accepted: 4 June 2018 / Published online: 2 July 2018

(c) The Author(s) 2018. This article is published with open access

Acquired whole chromosome/segmental uniparental disomies (wUPDs/sUPDs) are common in myeloid malignancies $[1,2]$. Already in the first publication on acquired UPDs in AML [1], it was reported that a case with UPD19q12-qter harbored a homozygous mutation in the CEBPA gene in 19q13.11 and, soon afterward, AML cases with sUPDs of $11 \mathrm{p}, 13 \mathrm{q}$, and $21 \mathrm{q}$ were shown to carry homozygous mutations of the WT1, FLT3, and RUNX1 genes [3]. There are now several examples of other UPDassociated homozygously mutated genes in myeloid malignancies, where heterozygous somatic mutations precede the mitotic recombination events [2].

UPDs occur with a similar frequency in BCP ALL as in AML ( 20\%) [4, 5]. However, next to nothing is known about the molecular consequences of UPDs in BCP ALL. UPD9p is the only UPD investigated in any detail in BCP ALL, where it is often associated with homozygous $C D K N 2 A$ deletions [4], and, to the best of our knowledge, UPD16p is the only UPD in BCP ALL that has been

Electronic supplementary material The online version of this article (https://doi.org/10.1038/s41375-018-0191-0) contains supplementary material, which is available to authorized users.

Kristina B. Lundin-Ström

Kristina.Lundin_Strom@med.lu.se

1 Division of Clinical Genetics, Department of Laboratory Medicine, Lund University, Lund, Sweden

2 Department of Clinical Genetics and Pathology, Division of Laboratory Medicine, Lund, Sweden

3 Present address: Division of Hematology, Skåne University Hospital and Wallenberg Centre for Molecular Medicine, Lund University, Lund, Sweden

4 Present address: Department of Pediatrics, Linköping University Hospital, Linköping, Sweden

5 Department of Pediatrics, Skåne University Hospital, Lund, Sweden recurrently shown to result in homozygosity of a mutated gene (CREBBP at 16p13.3) [6]. To ascertain whether UPDs in BCP ALL are associated with the presence of homozygous gene variants within the affected regions, we performed whole-exome sequencing (WES) analyses of 25 UPD-positive BCP ALL cases.

The acquired wUPDs and sUPDs were identified by single-nucleotide polymorphism array analyses of paired diagnostic/remission samples at the Department of Clinical Genetics and Pathology, Lund, Sweden, as previously reported [4]. The 25 cases comprised 10 with high hyperdiploidy (HeH; 51-67 chromosomes), 3 ETV6-RUNX1, 2 $B C R-A B L 1,2$ TCF3-PBX1, 1 with KMT2A rearrangement, and 7 with non-characteristic abnormalities/normal karyotypes (B-other), with a total of 16 wUPDs and 21 sUPDs. The wUPDs involved chromosomes $\mathrm{X}, 1,3,5,7,8,9,11$, 13, 16, and 19 and all but one were found in the $\mathrm{HeH}$ subgroup. None of the wUPDs was associated with a homozygous deletion. The sUPDs occurred in all genetic subgroups and affected chromosome arms 6p, 7p, 9p, 9q, 10q, 11q, 12p, 12q, 14q, 16p, 17p, 17q, 18q, and 19p. Four cases with UPD9p had homozygous $C D K N 2 A$ deletions (Supplementary Table 1).

WES was performed, as described in Supplementary Materials and Methods, on DNA extracted from bone marrow/peripheral blood cells obtained at diagnosis and during remission. The bioinformatic analyses focused on homozygous variants in the leukemic samples that were homozygously wild type in the paired remission samples, revealing a total of 373 putative somatic homozygous variants in 24/37 (65\%) UPDs (10 wUPDs and 14 sUPDs) in 15/25 (60\%) cases (\#1, 4-6, 8-14, 17, and 21-23; Supplementary Table 1). Although UPD16p has been shown to result in homozygosity of CREBBP in BCP ALL [6], case 1 with sUPD16p did not harbor any variants in this gene.

Among the 373 variants, the 173 (46\%) intragenic splicesite or exonic stop lost, deletions/insertions (delins), or nonsynonymous missense variants were selected for further 


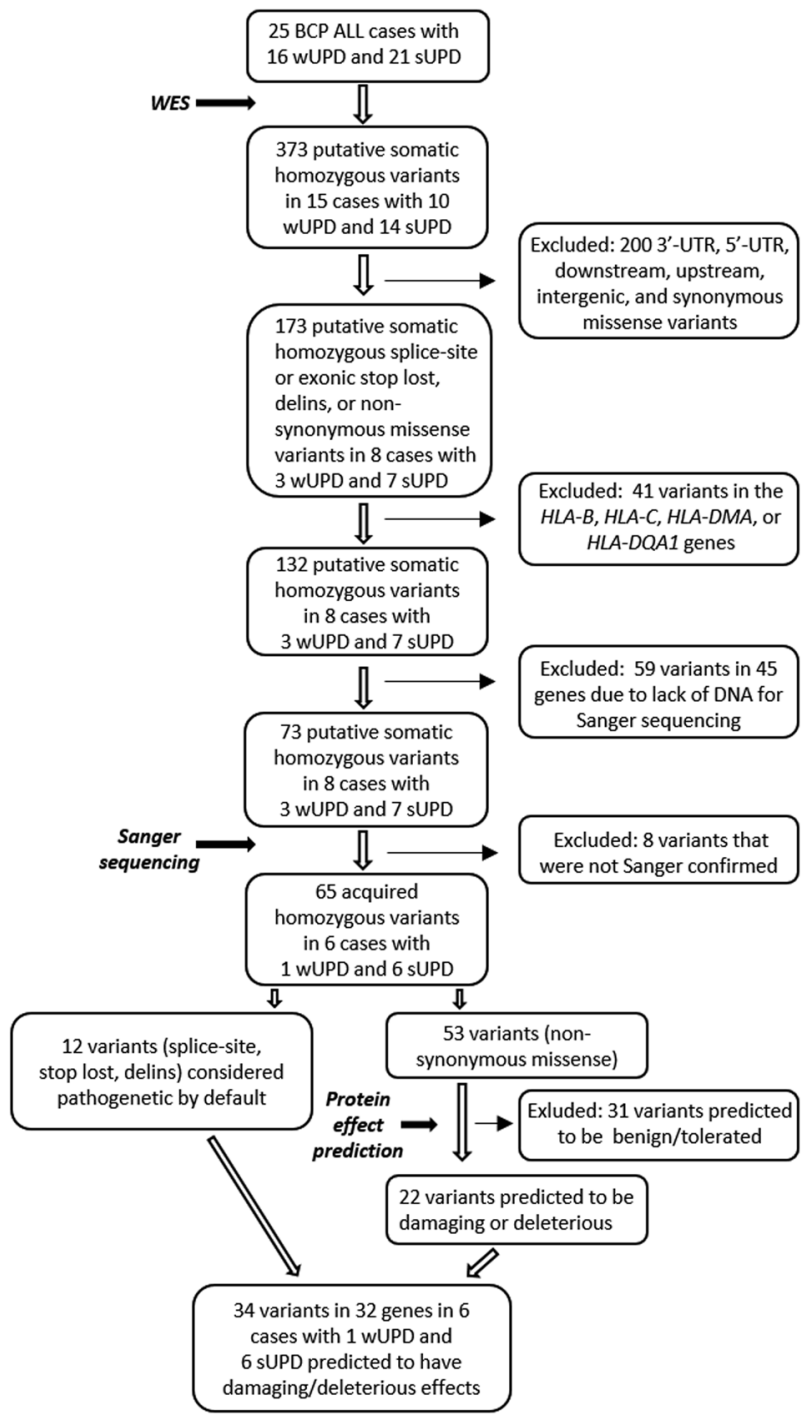

Fig. 1 Flowchart of the number of cases and wUPDs/sUPDs investigated in the various analysis steps

analysis (Fig. 1). Forty-one variants in different $H L A$ genes were excluded due to the highly polymorphic nature of these genes and the technical and bioinformatic challenges they present. This resulted in 132 candidate variants in eight cases, of which 128 (97\%) were associated with sUPDs involving $6 \mathrm{p}, 9 \mathrm{p}, 11 \mathrm{q}, 12 \mathrm{q}$, and $19 \mathrm{p}$ and four $(3 \%)$ with wUPDs of chromosomes 3 and 11 (cases 4, 5, 8, 11-13, 21, and 22; Supplementary Table 1). Sixty-five of the variants in 55 genes in six cases were confirmed, by Sanger sequencing (Supplementary Materials and Methods; Supplementary Tables 2 and 3), to be acquired (cases 4, 5, 12, 13, 21, and 22) (Fig. 1). The remaining variants could not be verified because of: (i) lack of DNA (59 variants; Supplementary Table 4); (ii) failed sequencing reactions (2 variants); (iii) six variants were not homozygous at diagnosis and wild type at remission.
The PolyPhen (http://genetics.bwh.harvard.edu/pph2/), PROVEAN (http://provean.jcvi.org/index.php), and SIFT (http://sift.jcvi.org/) software tools were used to predict whether the 65 Sanger-confirmed variants affected protein function. The 12 splice-site, stop lost, and delins were considered pathogenetic by default. Of the 53 nonsynonymous missense variants, 22 were predicted to be "possibly damaging", "probably damaging", "damaging", or "deleterious" by at least one of the three programs. In total, 34 UPD-associated acquired homozygous splice-site, stop lost, delins, and non-synonymous missense variants in 32 genes were predicted to have damaging/deleterious effects on their corresponding proteins (Fig. 1, Table 1). The variants occurred in 6 (24\%) of the 25 cases (4/7 (57\%) B-other cases, 1/2 (50\%) BCR-ABL1-positive cases, and 1/ $10(10 \%) \mathrm{HeH}$ cases), and were found in $7(19 \%)$ of the 37 UPDs (1/16 (6\%) wUPDs and 6/21 (29\%) sUPDs; cases 4, $5,12,13,21$, and 22; Table 1). Six variants (in the ATG7, DNAJC13, JAK2, SH2B3, UBAP2, and ZSCAN23 genes) were not listed in dbSNP Build 141 (https://www.ncbi.nlm. nih.gov/projects/SNP/snp_summary.cgi?build_id=141), whereas the remaining 28 damaging/deleterious gene variants have all been reported as germline variants in dbSNP Build 141. However, they were clearly somatic in our cases, not seen in matched remission samples.

The present study is the first to focus specifically on the possible association between UPDs and homozygous gene mutations in BCP ALL. WES analysis of UPD-positive BCP ALL cases identified a large number of candidate variants-most of which are probably "passengers". It is, however, noteworthy that $97 \%$ of the 132 candidate variants were associated with sUPDs and only $3 \%$ with wUPDs. This strongly indicates that the pathogenetic consequences of sUPDs and wUPDs differ. We have previously shown that wUPIDs in pediatric BCP ALL are restricted to the $\mathrm{HeH}$ subgroup, where they may reflect the underlying mechanism of the high hyperdiploid pattern in some cases, namely an initial tetraploidization followed by chromosome losses. This would result in a third of the disomies being wUPDs by chance alone [4]. Because the numerical abnormalities in $\mathrm{HeH}$ ALL are early, likely primary, events in the genesis of this subtype [7], the present finding of a general lack of homozygous variants in wUPDs may simply reflect that variants most often arise after wUPD formation and hence are heterozygous. It is, however, noteworthy that two homozygous variants associated with wUPD3 were identified in case 22; thus, they occurred prior to the wUPD event. The sUPDs, on the other hand, are probably later events in the leukemogenic process and hence more likely to duplicate somatically acquired variants.

The final set of 34 variants were observed in only $24 \%$ of the 25 BCP ALL cases and 19\% of the 37 UPDs, but were enriched in B-other cases and in sUPDs (Table 1). This 
Table 1 The 34 UPD-associated somatic homozygous variants in 32 genes predicted to have damaging/deleterious effects

\begin{tabular}{|c|c|c|c|c|c|c|c|c|c|c|}
\hline \multirow[t]{2}{*}{ Case no. } & \multirow[t]{2}{*}{ UPD } & \multirow[t]{2}{*}{ Gene symbol $^{\mathrm{a}}$} & \multirow{2}{*}{$\begin{array}{l}\text { Genetic } \\
\text { subgroup }\end{array}$} & \multirow{2}{*}{$\begin{array}{l}\text { Type of } \\
\text { variant }\end{array}$} & \multirow[t]{2}{*}{ Exon no. } & \multirow{2}{*}{$\begin{array}{l}\text { Protein } \\
\text { position }\end{array}$} & \multirow{2}{*}{$\begin{array}{l}\text { Amino-acid } \\
\text { change }\end{array}$} & \multicolumn{3}{|l|}{ Software tool } \\
\hline & & & & & & & & PROVEAN & SIFT & PolyPhen \\
\hline 4 & $11 q$ & $C B L$ & B-other & Delins & 9 & $460-461$ & $\begin{array}{l}\text { Deletion of } \\
\text { Asp }\end{array}$ & - & - & - \\
\hline 5 & $12 q$ & GRIP1 & B-other & Missense & 3 & 84 & $\operatorname{Arg} \rightarrow$ Gln & Deleterious & Damaging & $\begin{array}{l}\text { Probably } \\
\text { damaging }\end{array}$ \\
\hline 5 & $12 q$ & SH2B3 & “ & Delins & 6 & 396 & Premature stop & - & - & - \\
\hline 12 & $9 p$ & $J A K 2$ & B-other (DS) & Missense & 16 & 683 & Arg $\rightarrow$ Gly & Deleterious & Damaging & $\begin{array}{l}\text { Probably } \\
\text { damaging }\end{array}$ \\
\hline 13 & $9 p$ & CER1 & B-other & Missense & 1 & 19 & $\operatorname{Arg} \rightarrow \operatorname{Trp}$ & Neutral & Damaging & Benign \\
\hline 13 & $9 p$ & FREMI & “ & Missense & 10 & 465 & Gly $\rightarrow$ Ala & Deleterious & Damaging & $\begin{array}{l}\text { Probably } \\
\text { damaging }\end{array}$ \\
\hline 13 & $9 p$ & CNTLN & “ & Missense & 11 & 562 & Arg $\rightarrow$ Cys & Deleterious & Damaging & Benign \\
\hline 13 & $9 p$ & “ & “ & Splice-site & - & - & - & - & - & - \\
\hline 13 & $9 p$ & IFT74 & “ & Missense & 20 & 597 & $\mathrm{Thr} \rightarrow \mathrm{Ile}$ & Neutral & Damaging & Benign \\
\hline 13 & $9 p$ & $I F N K$ & “ & Delins & 1 & 13 & Premature stop & - & - & - \\
\hline 13 & $9 p$ & $D D X 58$ & “ & Missense & 1 & 7 & Arg $\rightarrow$ Cys & Deleterious & Damaging & $\begin{array}{l}\text { Probably } \\
\text { damaging }\end{array}$ \\
\hline 13 & $9 p$ & $U B A P 2$ & “ & Missense & 14 & 509 & $\operatorname{Arg} \rightarrow \operatorname{Trp}$ & Deleterious & Damaging & $\begin{array}{l}\text { Probably } \\
\text { damaging }\end{array}$ \\
\hline 21 & $6 \mathrm{p}$ & $H U S 1 B$ & $B C R-A B L 1$ & Missense & 1 & 201 & Gln $\rightarrow$ Arg & Neutral & Damaging & Benign \\
\hline 21 & $6 p$ & ВMP6 & “ & Missense & 1 & 96 & Leu $\rightarrow$ Pro & Neutral & Tolerated & $\begin{array}{l}\text { Possibly } \\
\text { damaging }\end{array}$ \\
\hline 21 & $6 \mathrm{p}$ & ATXN1 & “ & Missense & 8 & 753 & Pro $\rightarrow$ Ser & Neutral & Damaging & Benign \\
\hline 21 & $6 p$ & ZSCAN23 & “ & Splice-site & - & - & - & - & - & - \\
\hline 21 & $6 \mathrm{p}$ & $O R 2 W 1$ & “ & Missense & 1 & 81 & $\mathrm{Met} \rightarrow \mathrm{Val}$ & Neutral & Damaging & Benign \\
\hline 21 & $6 \mathrm{p}$ & $U B D$ & “ & Missense & 2 & 68 & $\mathrm{Ile} \rightarrow \mathrm{Thr}$ & Deleterious & Damaging & $\begin{array}{l}\text { Probably } \\
\text { damaging }\end{array}$ \\
\hline 21 & $6 \mathrm{p}$ & GTF2H4 & “ & Splice-site & - & - & - & - & - & - \\
\hline 21 & $6 \mathrm{p}$ & $C D S N$ & “ & Missense & 2 & 410 & Leu $\rightarrow$ Ser & Neutral & Tolerated & $\begin{array}{l}\text { Possibly } \\
\text { damaging }\end{array}$ \\
\hline 21 & $6 \mathrm{p}$ & STK19 & “ & Splice-site & - & - & - & - & - & - \\
\hline 21 & $6 p$ & NOTCH4 & “ & Delins & 1 & 15 & Deletion of Ser & - & - & - \\
\hline 21 & $6 \mathrm{p}$ & $T A P 2$ & “ & Stop lost & 12 & 687 & Stop $\rightarrow$ Gln & - & - & - \\
\hline 21 & $6 \mathrm{p}$ & RPL1OA & “ & Splice-site & - & - & - & - & - & - \\
\hline 21 & $6 \mathrm{p}$ & PNPLAl & “ & Missense & 6 & 193 & Glu $\rightarrow$ Gly & Deleterious & Damaging & $\begin{array}{l}\text { Possibly } \\
\text { damaging }\end{array}$ \\
\hline 21 & $6 p$ & РEX6 & “ & Missense & 13 & 809 & $\mathrm{Ala} \rightarrow \mathrm{Val}$ & Deleterious & Damaging & $\begin{array}{l}\text { Probably } \\
\text { damaging }\end{array}$ \\
\hline 21 & $19 p$ & TMIGD2 & “ & Missense & 3 & 138 & Pro $\rightarrow$ Leu & Deleterious & Tolerated & Benign \\
\hline 21 & $19 p$ & $S A F B 2$ & “ & Missense & 10 & 457 & $\mathrm{Thr} \rightarrow$ Ala & Deleterious & Damaging & Benign \\
\hline 21 & $19 p$ & FCER2 & “ & Splice-site & - & - & - & - & - & - \\
\hline 21 & $19 p$ & “ & “ & Splice-site & - & - & - & - & - & - \\
\hline 21 & $19 p$ & $R G L 3$ & “ & Missense & 5 & 162 & Pro $\rightarrow$ His & Deleterious & Damaging & $\begin{array}{l}\text { Probably } \\
\text { damaging }\end{array}$ \\
\hline 21 & $19 p$ & PALM3 & “ & Missense & 6 & 412 & $\mathrm{Thr} \rightarrow \operatorname{Arg}$ & Neutral & Damaging & $\begin{array}{l}\text { Possibly } \\
\text { damaging }\end{array}$ \\
\hline 22 & 3 & $A T G 7$ & $\mathrm{HeH}$ & Missense & 3 & 62 & $\mathrm{Arg} \rightarrow \mathrm{His}$ & Deleterious & Damaging & $\begin{array}{l}\text { Probably } \\
\text { damaging }\end{array}$ \\
\hline 22 & 3 & DNAJC13 & “ & Missense & 52 & 2039 & Pro $\rightarrow$ Ser & Deleterious & Damaging & Benign \\
\hline
\end{tabular}

DS Down syndrome, $\mathrm{HeH}$ high hyperdiploidy (51-67 chromosomes), UPD uniparental disomy

${ }^{\mathrm{a}}$ Genes previously reported to be involved in B-cell precursor acute lymphoblastic leukemia are indicated in bold type 
genetically and clinically heterogeneous group has received much attention in recent years, with the aim to subdivide it into homogeneous subtypes, on the basis of gene expression profiles and patterns of fusion genes, deletions, and mutations. As the present study shows, WES analyses of sUPDs in B-other cases may provide pertinent data in this regard by identifying genes of potential pathogenetic importance in this subtype.

None of the 32 genes targeted by the 34 variants was recurrently involved among the cases analyzed. Furthermore, only five of the targeted genes have previously been implicated in BCP ALL. BMP6 and FREM1 mutations have so far been reported in single BCP ALL cases only (https:// cancer.sanger.ac.uk/cosmic), whereas $C B L, J A K 2$, and $S H 2 B 3$ mutations are recurrent in BCP ALL. $C B L$ is rarely mutated in BCP ALL, but identifying cases with $C B L$ mutations may be clinically relevant because they have been shown to be associated with constitutive activation of the RAS pathway and to be sensitive to MEK inhibitors [8]. $J A K 2$ mutations, resulting in constitutive activation of the JAK-STAT signaling pathway, are present in $\sim 4 \%$ of BCP ALL in general but are particularly common ( 20\%) in BCP ALL in children with Down syndrome (DS) [9]. The single case with UPD9p and a homozygous JAK2 mutation in our cohort was also a DS-ALL (Table 1). In addition, this case had a homozygous $C D K N 2 A$ deletion associated with the UPD9p. This shows that a sUPD can result in homozygosity of two distinct gene changes; thus, one should not assume that UPD9p-associated homozygous $C D K N 2 A$ deletions are the only pathogenetically important consequences of this sUPD. SH2B3 plays an important role in the homeostasis of hematopoietic stem cells and lymphoid progenitors, and homozygous somatic $\mathrm{SH} 2 \mathrm{~B} 3$ mutations have previously been identified in ALL, suggesting a tumor suppressor role [10]. The underlying mechanism for the homozygosity of SH2B3 mutations has not been previously addressed, but, as seen herein, UPD12q is clearly one mechanism.

Among the 27 novel BCP ALL-associated genes identified, five have previously been implicated in other hematologic malignancies: DDX58 regulates proliferation of AML cells [11], ATXN1 and TAP2 polymorphisms are associated with increased risks of chronic lymphocytic leukemia and follicular lymphoma, respectively [12, 13], and deletion of $\operatorname{Atg} 7$ in a murine model results in a myeloproliferation resembling human AML [14]. Furthermore, NOTCH4 activation has been shown to lead to reduced differentiation and altered lymphoid development [15]. Thus, these genes may be of particular interest in BCP ALL. However, this remains to be elucidated, as does the potential impact of the other gene variants (Table 1).

In summary, we conclude that sUPDs in BCP ALL may highlight chromosomal regions carrying genes of importance in the leukemic process, particularly in the B-other group.
Funding This study was supported by the Swedish Cancer Society (CAN 2017/291), the Swedish Childhood Cancer Foundation (PR2015-0006), the Swedish Research Council (2016-01084), Governmental Funding of Clinical Research within the National Health Service (2014/354), and the Royal Physiographic Society of Lund.

Author contributions KBLS planned and performed research and wrote the paper; $\mathrm{AB}, \mathrm{HL}, \mathrm{MR}, \mathrm{TF}$, and $\mathrm{LO}$ performed research; $\mathrm{MH}$, $\mathrm{MB}$, and $\mathrm{AC}$ provided patient samples and clinical data; and $\mathrm{BJ}$ planned research and wrote the paper. The paper was reviewed and approved by all the authors.

Compliance with ethical standards The investigation was approved by the Research Ethics Committee of Lund University and informed consent for the analyses was obtained according to the Declaration of Helsinki.

Conflict of interest The authors declare that they have no conflict of interest.

Open Access This article is licensed under a Creative Commons Attribution 4.0 International License, which permits use, sharing, adaptation, distribution and reproduction in any medium or format, as long as you give appropriate credit to the original author(s) and the source, provide a link to the Creative Commons license, and indicate if changes were made. The images or other third party material in this article are included in the article's Creative Commons license, unless indicated otherwise in a credit line to the material. If material is not included in the article's Creative Commons license and your intended use is not permitted by statutory regulation or exceeds the permitted use, you will need to obtain permission directly from the copyright holder. To view a copy of this license, visit http://creativecommons. org/licenses/by/4.0/.

\section{References}

1. Raghavan M, Lillington DM, Skoulakis S, Debernardi S, Chaplin $\mathrm{T}$, Foot NJ, et al. Genome-wide single nucleotide polymorphism analysis reveals frequent partial uniparental disomy due to somatic recombination in acute myeloid leukemias. Cancer Res. 2005;65: $375-8$.

2. Score J, Cross NCP. Acquired uniparental disomy in myeloproliferative neoplasms. Hematol Oncol Clin North Am. 2012;26: 981-91.

3. Fitzgibbon J, Smith L-L, Raghavan M, Smith ML, Debernardi S, Skoulakis S, et al. Association between acquired uniparental disomy and homozygous gene mutation in acute myeloid leukemias. Cancer Res. 2005;65:9152-4.

4. Lundin KB, Olsson L, Safavi S, Biloglav A, Paulsson K, Johansson B. Patterns and frequencies of acquired and constitutional uniparental isodisomies in pediatric and adult B-cell precursor acute lymphoblastic leukemia. Genes Chromosomes Cancer. 2016;55:472-9.

5. Gupta M, Raghavan M, Gale RE, Chelala C, Allen C, Molloy G, et al. Novel regions of acquired uniparental disomy discovered in acute myeloid leukemia. Genes Chromosomes Cancer. 2008;47: 729-39.

6. Inthal A, Zeitlhofer P, Zeginigg M, Morak M, Grausenburger R, Fronkova E, et al. CREBBP HAT domain mutations prevail in relapse cases of high hyperdiploid childhood acute lymphoblastic leukemia. Leukemia. 2012;26:1797-803.

7. Paulsson K, Lilljebjörn H, Biloglav A, Olsson L, Rissler M, Castor A, et al. The genomic landscape of high hyperdiploid 
childhood acute lymphoblastic leukemia. Nat Genet. 2015;47: 672-6.

8. Nicholson L, Knight T, Matheson E, Minto L, Case M, Sanichar $\mathrm{M}$, et al. Casitas B lymphoma mutations in childhood acute lymphoblastic leukemia. Genes Chromosomes Cancer. 2012;51: $250-6$.

9. Kearney L, Gonzalez De Castro D, Yeung J, Procter J, Horsley $\mathrm{SW}$, Eguchi-Ishimae $\mathrm{M}$, et al. Specific JAK2 mutation (JAK2R683) and multiple gene deletions in Down syndrome acute lymphoblastic leukemia. Blood. 2009;113:646-8.

10. Perez-Garcia A, Ambesi-Impiombato A, Hadler M, Rigo I, LeDuc CA, Kelly K, et al. Genetic loss of $\mathrm{SH} 2 \mathrm{~B} 3$ in acute lymphoblastic leukemia. Blood. 2013;122:2425-32.

11. Jiang L-J, Zhang N-N, Ding F, Li X-Y, Chen L, Zhang H-X, et al. RA-inducible gene-I induction augments STAT1 activation to inhibit leukemia cell proliferation. Proc Natl Acad Sci USA. 2011;108:1897-902.
12. Auer RL, Dighiero G, Goldin LR, Syndercombe-Court D, Jones C, McElwaine S, et al. Trinucleotide repeat dynamic mutation identifying susceptibility in familial and sporadic chronic lymphocytic leukaemia. $\mathrm{Br} \mathrm{J}$ Haematol. 2007;136:73-79.

13. Cerhan JR, Fredericksen ZS, Novak AJ, Ansell SM, Kay NE, Liebow M, et al. A two-stage evaluation of genetic variation in immune and inflammation genes with risk of non-Hodgkin lymphoma identifies new susceptibility locus in 6 p21.3 region. Cancer Epidemiol Biomark Prev. 2012;21:1799-806.

14. Mortensen M, Watson AS, Simon AK. Lack of autophagy in the hematopoietic system leads to loss of hematopoietic stem cell function and dysregulated myeloid proliferation. Autophagy. 2011;7:1069-70.

15. Vercauteren SM, Sutherland HJ. Constitutively active Notch4 promotes early human hematopoietic progenitor cell maintenance while inhibiting differentiation and causes lymphoid abnormalities in vivo. Blood. 2004;104:2315-22.

Leukemia (2018) 32:2062-2065

https://doi.org/10.1038/s41375-018-0081-5

Acute lymphoblastic leukemia

\title{
Saracatinib impairs maintenance of human T-ALL by targeting the LCK tyrosine kinase in cells displaying high level of lipid rafts
}

\author{
Anne Buffière ${ }^{1,2}$ - Théo Accogli ${ }^{1}$ - Laetitia Saint-Paul ${ }^{1,2} \cdot$ Géraldine Lucchi $^{3} \cdot$ Benjamin Uzan $^{4,5} \cdot$ Paola Ballerini $^{6}$. \\ Jean-Noël Bastie ${ }^{1,2,7,8} \cdot$ Laurent Delva ${ }^{1,2} \cdot$ Françoise Pflumio ${ }^{4,5} \cdot$ Ronan Quéré $^{1,2}$
}

Received: 23 October 2017 / Revised: 10 January 2018 / Accepted: 16 January 2018 / Published online: 28 February 2018

(c) Macmillan Publishers Limited, part of Springer Nature 2018

Electronic supplementary material The online version of this article (https://doi.org/10.1038/s41375-018-0081-5) contains supplementary material, which is available to authorized users.

Ronan Quéré

ronan.quere@inserm.fr

1 UMR1231, Inserm / Université Bourgogne Franche-Comté, Dijon, France

2 Labex LipSTIC, Dijon, France

3 Present address: Plateforme de Protéomique, Université Bourgogne Franche-Comté, Dijon, France

4 Present address: UMR967, Inserm / CEA / Université Paris 7 / Université Paris 11, Fontenay-aux-Roses, France

5 LSHL, IRCM / CEA, Fontenay-aux-Roses, France

6 Assistance Publique-Hôpitaux de Paris, Laboratoire d'Hématologie, Hôpital Trousseau, Paris, France

7 Hôpital Universitaire François Mitterrand, Service d'Hématologie Clinique, Dijon, France

8 Hôpital Universitaire François Mitterrand, CRB Ferdinand Cabanne, BB-0033-00044 Dijon, France
T-cell acute lymphoblastic leukemia (T-ALL) is a hematological malignancy characterized by an excessive proliferation of immature T-cells. To achieve remission, patients typically undergo two years of chemotherapy inducing acute and chronic side effects. To reduce chemotherapy intensity in newly diagnosed patients and to efficiently treat relapsed patients, developing new therapies is essential [1]. Lipid rafts (LR) are cholesterol-enriched patches located in the plasma membrane and behave as platforms surrounding many proteins, which have a critical role in cell signaling driving cell fate. They represent a key component of the signal transduction pathway that contributes to signal intensity modulation in normal hematopoiesis [2] and in normal lymphoid Tcell functions [3-5]. Affecting LR has been suggested to be a promising therapeutic approach for the treatment of several hematological cancers [6-8], as well as for T-cell leukemia [9-11].

We analyzed the LR composition of T-ALL cells samples from PDX- (patient-derived xenograft-) mice. Cells displayed different levels of LR (low: $\mathrm{LR}^{\mathrm{lo}}$, high: $\mathrm{LR}^{\mathrm{hi}}$ ) upon staining with cholera toxin subunit B (CTB), which is known to bind to 